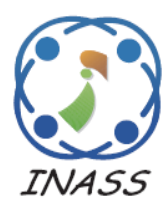

\title{
Islanding Detection Method of a Photovoltaic Installation Destined to Power a RLC Load and Integrated to LV Network
}

\author{
Fatima Chanaa ${ }^{1 *}$ \\ Radouane N'ait Zarri ${ }^{2}$ \\ Rachid Bendaoud ${ }^{1}$ \\ Houssam Amiry ${ }^{1}$ \\ Elhadi Baghaz ${ }^{1}$ \\ Said Bounouar ${ }^{1}$ \\ Bouchaib Zohal ${ }^{1}$ \\ Charaf Hajjaj ${ }^{3}$ \\ Said Yadir ${ }^{4}$ \\ Abderrahim El-abidi ${ }^{4}$ \\ Mohammadi Benhmida ${ }^{1}$
${ }^{1}$ Laboratory of Electronics, Instrumentation and Energetic, Department of physics, Faculty of Sciences, Chouaïb Doukkali University, El Jadida, Morocco
${ }^{2}$ OCP Group, Direction Jorf Nord, Technical Methods du site de Jorf Lasfar, El Jadida, Morocco
${ }^{3}$ Laboratory of Applied Sciences for the Environment and Sustainable Development, Higher School of Technology of Essaouira, Cadi Ayyad University, Essaouira, Morocco
${ }^{4}$ Laboratory of Materials, Processes, Environment and Quality, National School of Applied Sciences, Cadi Ayyad University, Safi, Morocco
* Corresponding author’s Email: fatima.chanaa.ing@gmail.com

\begin{abstract}
The islanding of grid-connected photovoltaic (PV) installations is a difficult problem that leads to many protection and security problems. A variety of islanding detection methods (IDMs) are proposed in several studies and these techniques are categorized into passive, active and communication based methods. This study describes the IDM adopted to detect islanding situation in the new PV installation connected to LVs grid of OCP Group (Cherifian Office for Phosphates in Morocco), global leader in the phosphate and phosphate derivatives markets. After having defined the way in which the PV generators will be integrated within the OCP Group grid, the causes that could lead to islanding situation are established. The comparison on the most used methods for islanding detection in the grid connected photovoltaic system (PV) is based on three parameters: the Non-Detection Zone (NDZ), the Detection Duration Time (DDT) and Total Harmonic Distortion (THD) of each method. These performance criteria are compared with the limit thresholds authorized by the IEEE 1574 standard, which are 5\% for THD and 2 seconds for DDT. The Slip Mode Frequency Shift (SMS) method is demonstrated to be the most effective, for our installation, among the simulated methods, with THD and DDT of $1.3 \%$ and $0.28 \mathrm{~s}$, respectively.
\end{abstract}

Keywords: Islanding detection, Photovoltaic installation, Non-detection zone, Total harmonic distortion.

\section{Introduction}

More than seventeen Tera-watt-hour (TWh) is currently considered to be the total energy consumption in the world at any given point in time
(Fig. 1), and it is expected to be twice as high by 2050 [1].

Since the demand is getting increasingly high, all kinds of energy are to be quickly increased in the coming years, for instance, solar photovoltaic (PV)

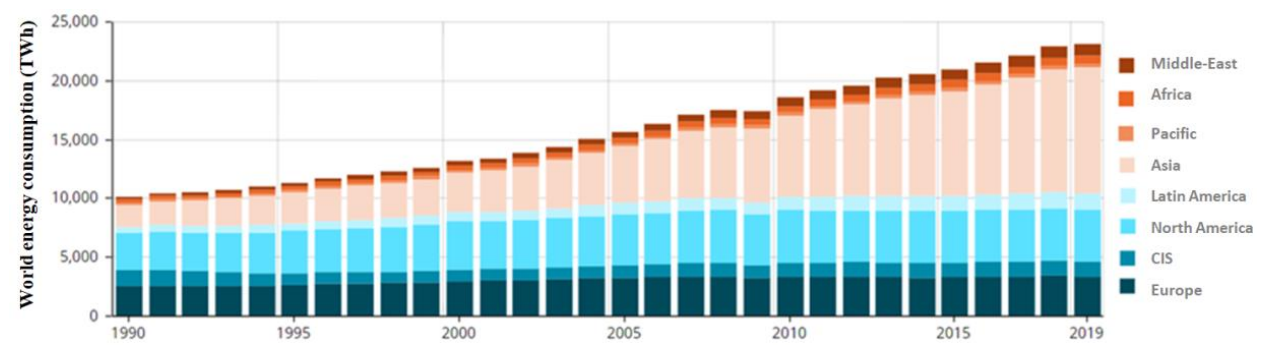

Figure. 1 Evolution of world energy consumption (TWh) 
systems may generate up to $16 \%$ of the world's electricity by 2050 [1].

One of the main concerns of grid-connected photovoltaic installations is islanding detection [2]. This phenomenon is enforced by grid interconnection standards such as IEEE 1547 [3], UL1741 [4], IEEE 929-2000 [5].

\subsection{Concept of islanding, causes and con- sequences}

According to the standards cited above [3-5], islanding is "a condition in which a portion of the electrical network comprising production means and loads is disconnected from the main network (separated from the upstream network) and the loads of this island are entirely supplied by the generators of the same island".

It is noted that the notion of island is associated with duration. The rules which define the operation of a PV installation consider that an islanding situation is defined as such as soon as the PV inverter detects operation in a separate network for a certain time (5 seconds according to DIN VDE 0126-1-1 [6], 2 seconds according to IEC 62116 [6]. Beyond this duration, the inverter must disconnect from the main grid.

Several configurations are theoretically possible depending on the size of the network or the electrical installation being separated from the upstream network (Fig. 2) [6]:

Islanding of a building: would occur in the event that a building is separated from the Low-Voltage (LV) or Medium-Voltage (MV) network, following for example the opening of the connection circuit breaker, and where a PV installation continues to supply the loads of this building.

Islanding of a $\mathbf{L V}$ departure: would occur in the event that a LV feeder would be separated from the MV network, for example following the removal of the HPC fuses to protect the LV feeder, and where one or more PV installations would continue to supply the connected loads on this LV departure.

Islanding of an MV departure: would occur in the event that an MV is separated from the HighVoltage (HV) network, following for example the opening of the MV protection circuit breaker, and where one or more PV installations continue to supply the connected loads on this MV departure.

Unintentional islanding can have various consequences [7-8]:

- During maintenance periods, it could compromise the safety of personnel working on site if the rules for verifying the absence of voltage in the conductors and earthing were not strictly observed;

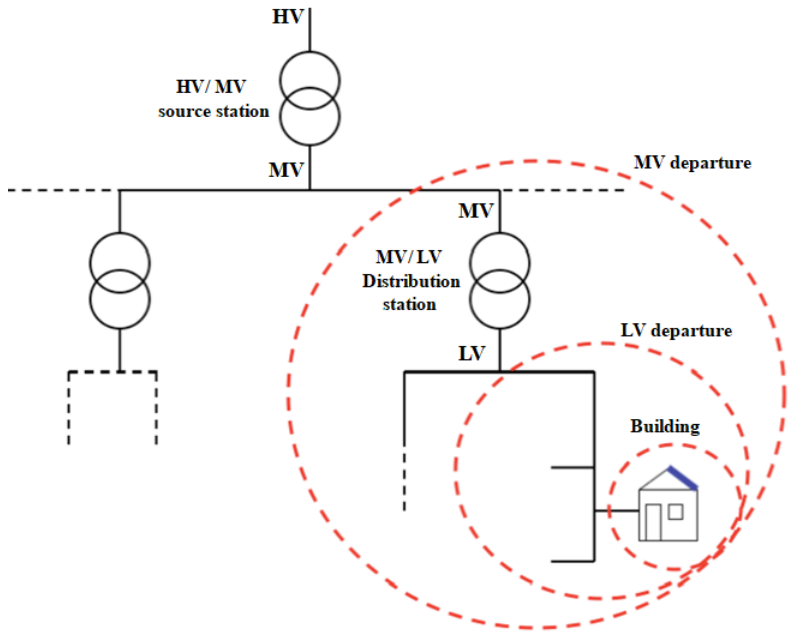

Figure. 2 Different network sizes that can be separated from the upstream network and be in islanding situation

- Since the voltage and frequency in the island are no longer controlled by the network operators, they can go outside regulatory limits and cause damage to the electrical installations present in this island;

- It can also disturb the restocking of the island when the upstream network is put back into service (a phase difference between the upstream and downstream voltages could in particular generate high currents).

\subsection{Context and goal of the present work}

As part of a project within OCP Group Morocco, world leader in the phosphate industry, we were led to study the feasibility and the impact of PV system integration within the electrical network of MOROCCO PHOSPHORE (MP) entity of OCP in order to power new restaurant and to increase the lighting rate in the MP entity.

The energy balance for the production and consumption of MP entity is shown in Fig. 3.

From the energy balance, it can be concluded that in recent years, MOROCCO PHOSPHORE (MP) entity has become deficit in terms of energy, and in terms of cost the energy bill is quite high.

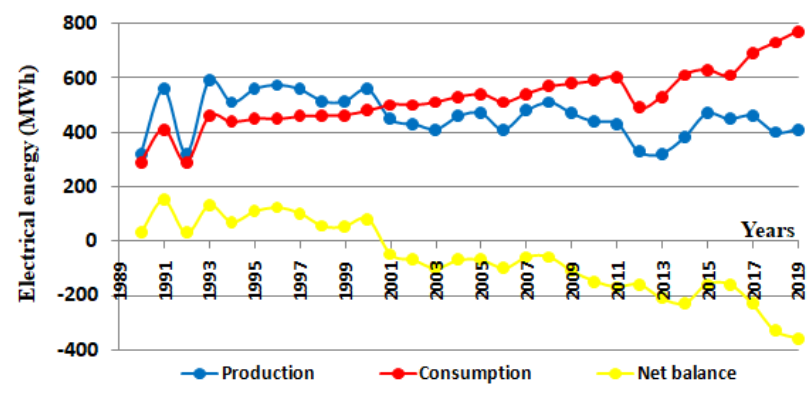

Figure. 3 Net electrical energy balance of MOROCCO PHOSPHORE (MP) entity 
For the reasons mentioned above, we were asked to study the feasibility of supplying the new load using solar energy.

As part of the project, the aim of this work is to study the islanding situation of the PV generators to be integrated to LV network of OCP and present the solution adopted for the detection of this phenomenon.

In order to successfully accomplish this mission, we have proceeded as follows: A classification of all island detection methods, into passive, active and communication based methods is done and then the way in which the PV generators will be integrated to the network of OCP group is defined in order to establish the causes that could lead to such situation. A comparative study on the most used methods for islanding detection in the grid connected photovoltaic system (PV), based on the Detection Duration Time (DDT), the Non-Detection Zone (NDZ) and Total Harmonic Distortion (THD) of each method, is provided. A mathematical calculation of ZND of passive and active methods is also detailed in this paper. Then the solution adopted for the detection of this problem to protect our installation is presented.

The proposed approach was examined and tested by numerical simulation using Matlab / Simulink.

\section{Grid connected photovoltaic islanding detection review}

According to IEEE 929-1988 [9] and IEEE 15472003 [10] standards, the photovoltaic system must be disconnected once it is islanded with maximum delay of 2 seconds for detection of an unintentional island. A variety of islanding methods are proposed in several studies [11-15] and these techniques are categorized into three classifications: passive methods, active methods and communication based methods [16].

\subsection{Passive methods}

Those methods are built on tracking the grid parameters by detecting abnormal changes in frequency, voltage or phase angle and, in some specific harmonics, the total harmonic distortion (THD) [17-19]. The inverter will trip if there is a large or sudden change of these variables at a point of connection with the utility grid PCC (Point of Common Coupling) as described in the flow chart laid out in Fig. 4.

The limits of the voltage, frequency and THD according to IEEE 1547 are given in Table 1.

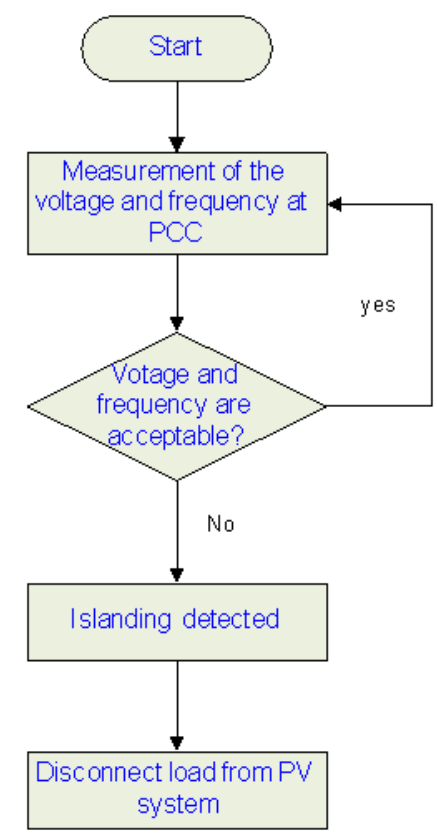

Figure. 4 Flow chart of the passive methods based on voltage and frequency measurement

Table 1. Parameters and limits used in the passive methods [17]

\begin{tabular}{|c|c|}
\hline \multicolumn{2}{|c|}{ Disconnection time for voltage variations } \\
\hline $\mathrm{V}<50$ & $0.16 \mathrm{~s}$ \\
\hline $50 \leq \mathrm{V}<88$ & $2.00 \mathrm{~s}$ \\
\hline $110<\mathrm{V}<120$ & $1.00 \mathrm{~s}$ \\
\hline $\mathrm{V} \geq 120$ & $0.16 \mathrm{~s}$ \\
\hline \multicolumn{2}{|c|}{ Disconnection time for frequency variations } \\
\hline $59.3<\mathrm{f}<60.5$ & $0.16 \mathrm{~s}$ \\
\hline \multicolumn{2}{|l|}{ Power Quality } \\
\hline Total harmonic distortion & THD $(\%)<5 \%$ \\
\hline \multicolumn{2}{|c|}{ Islanding detection } \\
\hline \multicolumn{2}{|c|}{$\begin{array}{l}\text { Inverter must shut down in less than } 2 \text { seconds under } \\
\text { islanding conditions }\end{array}$} \\
\hline
\end{tabular}

\subsection{Communication based methods}

The main communication based methods are: Transfer Trip scheme and Power Line Carrier based detection [20-21]. The first method is built on the ratio of the condition of the circuit breakers at the utility grid to the PV control system [20]. The second one is communication-based method in which the basic operation consists of sending a low-energy signal between the transmitters installed on the utility side and receiver installed on the PV side [21]. When islanding happens, the power and signal are concurrently disconnected from the grid as described in the chart flow laid out in Fig. 5.

These islanding detection methods have no NDZ. However, the communication equipment required for these methods is unprofitable as they are quite costly for the small PV plant. 


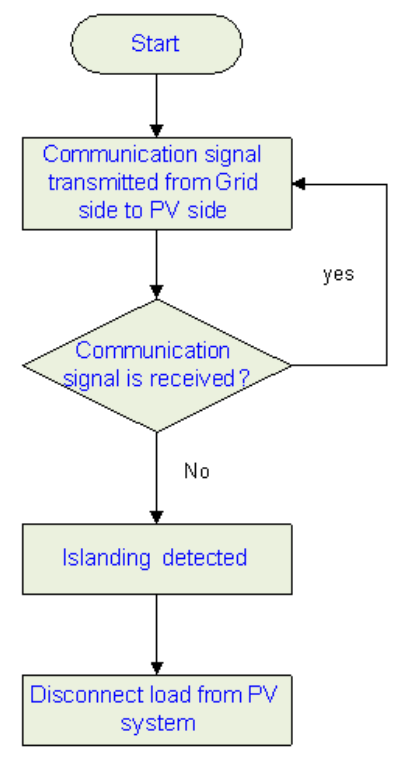

Figure. 5 Flow chart of communication methods

\subsection{Active methods}

The active methods are built on injecting a small disruption into the utility grid and, depending on the grid response, decide whether an island has occurred or not. The Active Frequency Drift (AFD) method, the Sandia Frequency Shift (SFS) method and the Slip Mode Frequency Shift (SMS) method are the most common active methods used [22-23]. The flow chart of this type of methods used for the islanding detection of the grid PV connected is given in Fig. 6 .

\section{Mathematical calculation of non detection zone}

NDZ is considered as the main performance factor that characterizes the operational capability of an IDM. It corresponds to the area for which islanding cannot be detected by the protection of an inverter without a specific control function or detection algorithm [6].

As the communication based method is unprofitable and quite costly for the new installation (small PV plant), this section is a mathematical calculation of the NDZ of the passive methods and the active ones.

The simulated system is presented in Fig. 7. It is composed of:

- a PV module,

- an inverter connected to PCC and works in the current control mode,

- a parallel RLC load,

- an utility grid provides the voltage and the frequency references.

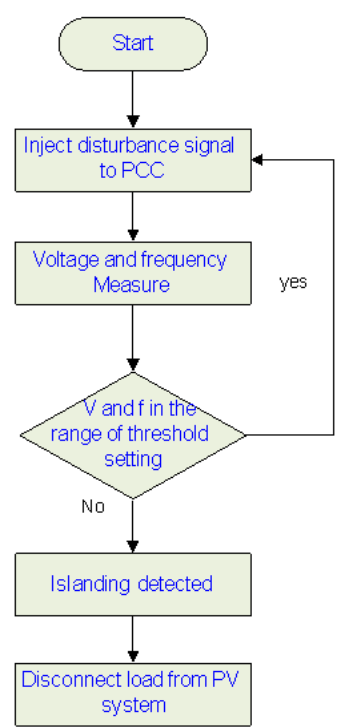

Figure. 6 Flow chart of the active islanding detection methods

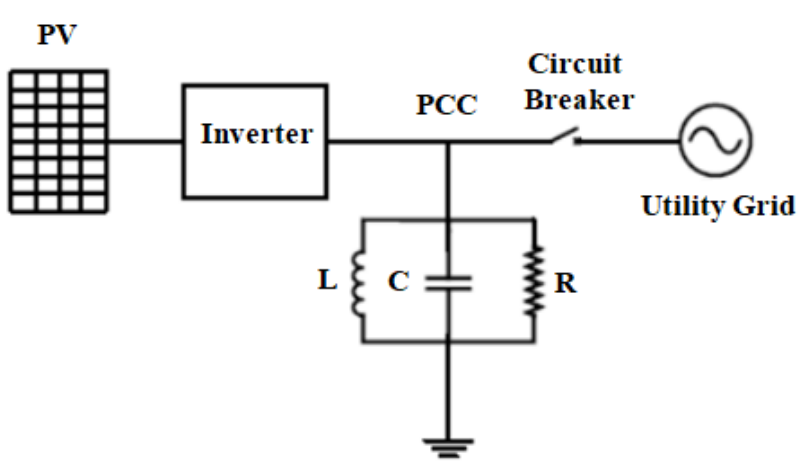

Figure. 7 Principal components of the simulated system

\subsection{NDZ of passive methods in $\Delta \mathrm{P}$ and $\Delta \mathrm{Q}$ space}

The NDZ of the passive methods depends on the values of Load quality factor $Q_{f}$, the active and reactive power disbalance $(\Delta P, \Delta Q)$ between the PV generation and the load demand. It can be expressed as follows [24]:

$$
\begin{gathered}
Q_{f} \times\left(1-\left(\frac{f}{f_{\min }}\right)^{2}\right) \leq \frac{\Delta Q}{P} \leq Q_{f} \times\left(1-\left(\frac{f}{f_{\max }}\right)^{2}\right)(1) \\
\left(\frac{V}{V_{\max }}\right)^{2}-1 \leq \frac{\Delta P}{P} \leq\left(\frac{V}{V_{\text {min }}}\right)^{2}-1
\end{gathered}
$$

Where $P$ is the rated active power of the PV and $\left(f_{\max }\right.$ min $)$ are the under/over frequency threshold.

Based on IEEE 1741 Standard:

$$
\begin{array}{ll}
V_{\max }=110 \% \times V_{n}, & f_{\max }=60.5 \mathrm{~Hz} \\
V_{\min }=88 \% \times V_{n}, & f_{\min }=59.3 \mathrm{~Hz}
\end{array}
$$


For an RLC load with $Q_{f}=2.5$ :

$$
\begin{aligned}
17.36 \% \leq \frac{\Delta P}{P} & \leq 29.13 \% \text { and }-5.94 \% \leq \frac{\Delta Q}{P} \\
& \leq 4.11 \%
\end{aligned}
$$

That means a large non detection zone NDZ. Moreover, The NDZ area of passive IDMs is sensitive to the value of $Q_{f}$. However their main advantage is that they do not affect the power quality.

\subsection{NDZ of the active methods in $Q_{f}$ and $f_{0}$ space}

It can be concluded, from Section 3.1, the NDZ area depends on the value of quality factor. Mapping the NDZ in the $Q_{f}$ and $f_{0}$ (resonance frequency of the load) space could be the best way to compare between different NDZ methods [6].

The phase angle of the load is equal to the phase angle of the inverter current when the final steady state frequency occurs:

$$
\theta_{\text {load }}(f)=\theta_{\text {inv }}(f)
$$

For a parallel RLC Load:

$$
\theta_{\text {load }}(\mathrm{f})=\tan ^{-1}\left(\mathrm{R}\left(\frac{1}{\omega \mathrm{L}}-\omega \mathrm{C}\right)\right)
$$

This can be expressed as:

$$
\begin{gathered}
\theta_{\text {load }}(f)=\tan ^{-1}\left[Q_{\mathrm{f}}\left(\frac{f_{0}}{\mathrm{f}}-\frac{\mathrm{f}}{\mathrm{f}_{0}}\right)\right] \\
\text { with: } \omega_{0}=\frac{1}{\sqrt{L C}}=2 \pi f_{0}
\end{gathered}
$$

This can be simplified by taking the tangent of both sides as follow in the steady state:

$$
\mathrm{f}_{0}^{2}+\frac{\mathrm{f}}{\mathrm{Q}_{\mathrm{f}}} \tan \left(\theta_{\text {inv }}(\mathrm{f})\right) \mathrm{f}_{0}-\mathrm{f}^{2}=0
$$

The calculation of NDZ is done by setting the islanding frequency $f$ to the frequency threshold $\left(f_{\min }, f_{\max }\right)$ and then, the $f_{0}$ can be calculated as follows [6]:

$$
\begin{aligned}
& f_{0}= \\
& \frac{f}{2 Q_{f}}\left(\sqrt{\tan \left(\theta_{i n v}(f)\right)^{2}+4 Q_{f}^{2}}-\tan \left(\theta_{i n v}(f)\right)\right)
\end{aligned}
$$

\subsubsection{NDZ of AFD method}

In this method [25]:

$$
\begin{gathered}
\theta_{\text {inv }}(f)=\theta_{\text {load }}(f)=\theta_{A F D}=\pi t_{z} f= \\
\pi f\left[\frac{1}{f}-\frac{1}{f+\delta f}\right]=\frac{\pi \delta f}{f+\delta f}
\end{gathered}
$$

Where $t_{z}$ is the dead time of the AFD method and $\delta f$ is the AFD frequency perturbation. The nondetection zone is obtained in $\left(f_{0}, Q_{f}\right)$ space for different value of $\delta f$.

$\left(f_{0, \min }, f_{0, \max }\right)$ of this method is calculated as follows:

$$
\begin{gathered}
f_{0, \text { max }}=\frac{f_{\max }}{2 Q_{f}}\left[\begin{array}{c}
-\tan \left(\frac{\pi \delta f}{f_{\max }+\delta f}\right)+ \\
\sqrt{\tan ^{2}\left(\frac{\pi \delta f}{f_{\max }+\delta f}\right)+4 Q_{f}^{2}}
\end{array}\right] \\
f_{0, \text { min }}=\frac{f_{\min }}{2 Q_{f}}\left[\begin{array}{c}
-\tan \left(\frac{\pi \delta f}{f_{\min }+\delta f}\right)+ \\
\sqrt{\tan ^{2}\left(\frac{\pi \delta f}{f_{\min }+\delta f}\right)+4 Q_{f}^{2}}
\end{array}\right]
\end{gathered}
$$

\subsubsection{NDZ of SFS method}

In this method [26]:

$$
\begin{gathered}
\theta_{\text {inv }}(f)=\theta_{\text {load }}(f)=\theta_{S F S} \\
=\frac{\omega t_{z}}{2}=\pi f t_{z}=\frac{\pi C_{f}}{2} \\
=\frac{\pi}{2}\left[C_{f 0}+K\left(f_{n}-f\right)\right]
\end{gathered}
$$

Where $K$ is the acceleration gain, $C_{f_{0}}$ is the chopping factor when there is no frequency error and $\left(f_{n}-f\right)$ is the difference between the estimated frequency and nominal value.

$\left(f_{0, \min }, f_{0, \max }\right)$ is calculated as follows:

$f_{0, \text { max }}=$
$\frac{f_{\max }}{2 Q_{f}}\left[\begin{array}{c}-\tan \left(\frac{\pi}{2}\left[C_{f 0}+K\left(f_{n}-f_{\max }\right)\right]\right)+ \\ \sqrt{\tan ^{2}\left(\frac{\pi}{2}\left[C_{f 0}+K\left(f_{n}-f_{\max }\right)\right]\right)+4 Q_{f}^{2}}\end{array}\right.$

$f_{0, \text { min }}$
$2 Q_{f}$$\left[\begin{array}{c}-\tan \left(\frac{\pi}{2}\left[C_{f 0}+K\left(f_{n}-f_{\text {min }}\right)\right]\right)+ \\ \tan ^{2}\left(\frac{\pi}{2}\left[C_{f 0}+K\left(f_{n}-f_{\text {min }}\right)\right]\right)+4 Q_{f}^{2}\end{array}(11)\right.$

\subsubsection{NDZ of SMS method}

In this method [27]: 


$$
\begin{gathered}
\theta_{\text {inv }}(f)= \\
\theta_{\text {load }}(f)=\theta_{S M S}=\theta_{m} \sin \left[\frac{\pi}{2} \times \frac{f-f_{n}}{f_{m}}\right]
\end{gathered}
$$

$\theta_{m}$ is the maximum phase shift, $f_{m}$ is the frequency at which the maximum phase shift occurs, $f$ is the system operating frequency, and $f_{n}$ is the utility normal operating frequency of $50 \mathrm{~Hz}$. The nondetection zone is obtained in $\left(f_{0}, Q_{f}\right)$ space for $f_{m}$ value of 3 and different value of $\theta_{m}$.

$\left(f_{0, \min }, f_{0, \max }\right)$ is calculated as follows:

$$
\begin{aligned}
& f_{0, \max } \\
& =\frac{f_{\text {max }}}{2 Q_{f}}\left[\sqrt{-\tan \left(\theta_{m} \sin \left[\frac{\pi}{2} \times \frac{f_{\text {max }}-f_{n}}{f_{m}}\right]\right)+}\right] \\
& f_{0, \text { min }} \\
& =\frac{f_{\text {min }}}{2 Q_{f}}\left[\sqrt{-\tan \left(\theta_{m} \sin \left[\frac{\pi}{2} \times \frac{f_{\text {min }}-f_{n}}{f_{m}}\right]\right)+}\right]
\end{aligned}
$$

\section{Integration of a new PV installation in electrical network of OCP Group}

\subsection{Description of the plant and location of the New PV Installation}

As our photovoltaic installation is to be connected to a three-phase low voltage $230 / 400 \mathrm{~V}$ network to supply the new loads and inject the surplus, it is essential to define its location within the internal network of the thermal power plant and the Bus-Bar through which it will be connected to the network. Since the $10 / 0.4 \mathrm{kV}$ transformers have the capacity to support the new loads, it is proposed to integrate the PV system as shown in Fig. 8.

The plant of MOROCCO PHOSPHORE (MP) entity is connected to the internal high-voltage $60 \mathrm{kV}$ electrical network, which is connected to the ONEE (National Office of Electricity and Drinking Water in MOROCCO) national network via the ONEE1 and ONEE2 stations (Fig. 8). It has three TurboGenerator Groups (TGGs) to produce enough energy to meet the plant's consumption and to ensure its energy autonomy when operating in islanding mode (disconnected from the ONEE national network).
The $60 \mathrm{kV}$ Bus-Bars supply the three main $10 \mathrm{kV}$ switchboards and another emergency switchboard which has the role of backing up one of the other switchboards if a problem occurs.

The PV installation will be connected to the network through the two transformers 23EC23 and 23EC24. These transformers are supplied by switchboard 23EM15.

The connection of the Photovoltaic Groups (PVGs) to the network will be ensured by the use of a Bus-Tie Breaker (BTB_PV) (Fig. 8).

\subsection{Operating modes of the thermal power plant and the PVGs}

\subsubsection{Mode 1: Normal operation of the thermal power plant}

This operating mode is characterized by the presence of the three electric power sources: the ONEE grid, the three TGGs and the PV generators PVGs (Fig. 9a). The PV generator feeds the new loads and in case of surplus, it injects it into the BusBar of the switchboard MV23EM15, and in the event of a deficit the three TGGs will ensure the continuity of the supply of these loads, provided that these TGGs are in surplus, if this is not the case it is the ONEE network which will ensure the continuity of energy supply necessary for all the loads.

\subsubsection{Mode 2: Islanding of the thermal power plant} (case of excess installation)

As for this operating mode (Fig. 9b), following disturbances from the ONEE network and which may cause risks for the equipment, the thermal power plant is isolated from the ONEE network. In this case one of the three TGGs of the central unit will take the relief to adjust the frequency (Master) and the other two TGGs will be slaves, as they will follow the orders of the master TGG and will consider it as the new reference instead of the ONEE network. As for the photovoltaic generator too, it will consider the master TGG as a reference and therefore it continues to supply its loads in a normal way and injects the surplus into the Bus-Bar concerned. The method used to detect islanding conditions, for this operating mode, consists in measuring the voltage using two MIC9 relays of the P923 AREVA type installed at ONEE1 and ONEE2, and comparing it to a predefined threshold to determine whether the system is in a islanding situation or not; if the voltage measured at the two arrivals drops by $80 \%$ or exceeds $110 \%$ of the nominal voltage, then the coupling circuit breaker opens, which causes islanding of the thermal power plant and the PV installation from the 


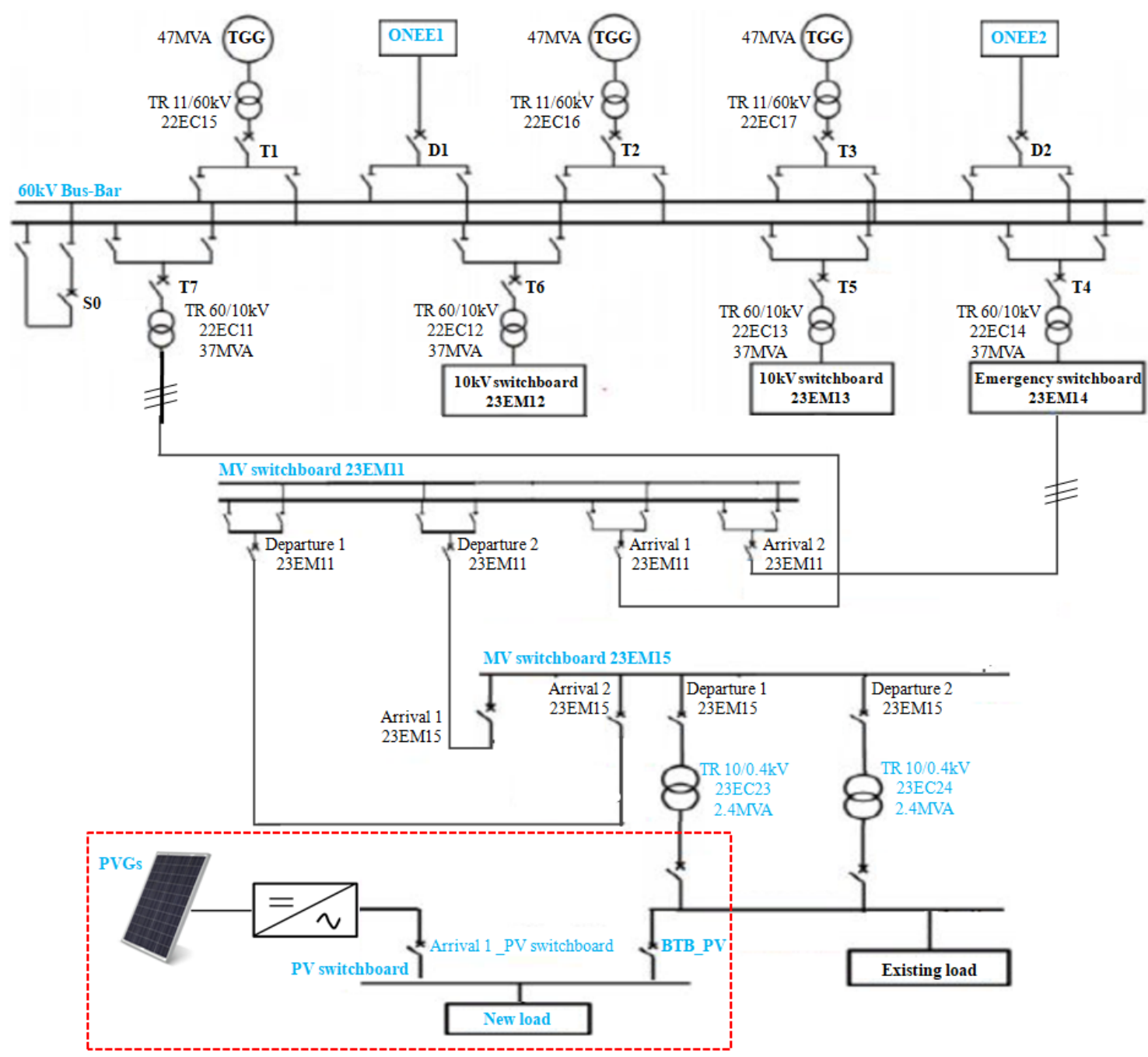

Figure. 8 Single-line electrical diagram of the PV system integration zone in the thermal power plant of MOROCCO PHOSPHORE entity

ONEE electrical network.

\subsubsection{Mode 3: Islanding of the thermal power station (case of loss-making installation)}

The causes leading to this type of operation are similar to those of mode 2 (Fig. 9c), but the difference is that in this mode the power plant is energy deficient, and therefore a load shedding procedure will take place in order to ensure the balance of all the installation.

The purpose of load shedding is to voluntarily stop supplying one or more non-critical (nonpriority) loads, in order to restore the balance between energy production and consumption. It is a safeguard measure intended to avoid the risks of collapse in voltage or frequency which could cause the tripping of the Turbo-Alternator and the total shutdown of the installation (blackout).

The load shedding is done such that the loads are relieved according to notches; the thing that avoids the cut of a number of consumers more than necessary. However, the load shedding procedure is ensured by a digital load shedding relay MICOM P922 which monitors the frequency of the TGGs: Once the frequency is less than $49 \mathrm{~Hz}$, it gives the load shedding order to a notch for a well-defined time delay. If this condition persists, it gives the order to shed the next notch and so on. Among the switchboards that will be unloaded, there is MT 23 EM 15.

\subsubsection{Mode 4: Total triggering of the complex}

It can also be called: Blackout situation, it is defined by the absence of the three TGGs and the ONEE network (Fig. 9d). Following a disturbance at the level of the ONEE network, the complex is spinning up, but due to the lack of steam, the consumption of loads exceeds production; which causes the load shedding, but when the load shedding reaches its maximum then the TGGs trigger and therefore the 


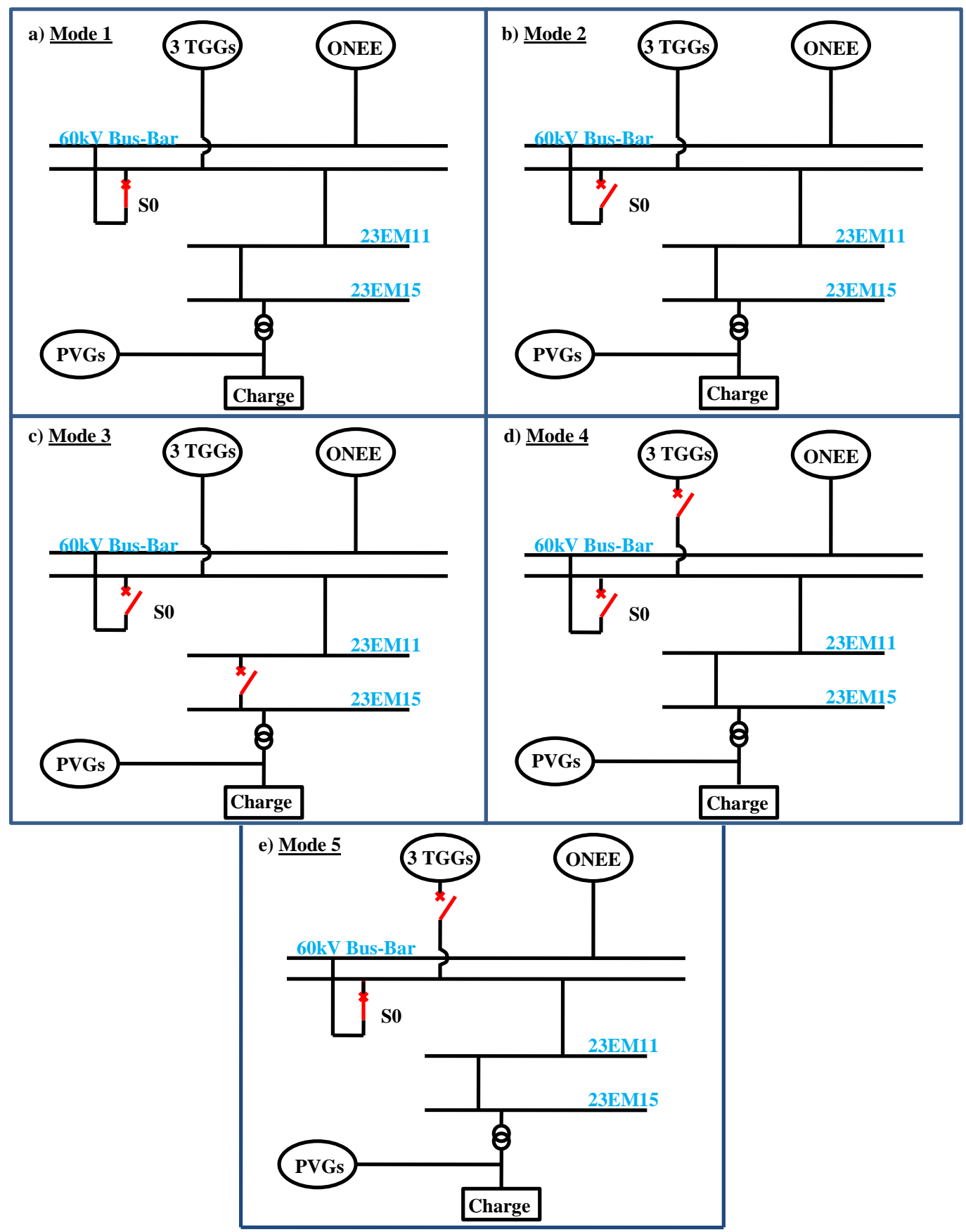

Figure. 9 Operating modes of the thermal power plant and the PVGs

blackout situation appears and the starting of the generator sets will be necessary in order to supply the most critical loads (lighting, chargers, tackers TGGs, signage, etc.).

\subsubsection{Mode 5: Powering of the complex by ONEE}

This operating mode is characterized by the absence of the three TGGs, and it is the ONEE network alone which ensures the supply of the complex and of the loads supplied by the PV generator in the event of a deficit of the latter (Fig. $9 \mathrm{e})$. For example, the restoration of the complex's power supply after the blackout is done by going through this operating mode.

\section{PV installation islanding and the proposed solution}

\subsection{Islanding of the new PV system}

The photovoltaic installation can be affected by the operating modes of the thermal power plant of MP entity, because in certain modes, the PV installation is unintentionally isolated from the electrical network, which requires the provision of a 
system that will have the ability to detect this situation in the shortest possible time. Here are the cases in which the photovoltaic installation can be in islanding situation:

Blackout: Only the photovoltaic generators continue to supply their load but the problem is that such a situation is dangerous in case of excess installation.

Load shedding of the switchboard MV23EM15: It is linked to operation in Mode 3; in fact the shedding of this switchboard leads to cut the supply to the BusBar connected to the new PV system.

Disturbances in the internal network of the thermal power plant: The islanding caused in this case is due to tripping of the circuit breakers by the protection devices (protection relays, etc.), when an internal fault occurs in the network power plant, in most cases it is:

- Short circuit or broken cables;

- Electric overload;

- Faults in transformers: overload, internal shortcircuit, tank mass, etc.

All these faults are controlled by protection relays which act on the circuit breakers by opening the latter in order to eliminate these faults, which can put the new installation in an islanding situation.

\subsection{Adopted method for PV system islanding detection integrated in OCP grid}

The photovoltaic installation must have an efficient system to detect the islanding situation caused by tripping of one of the circuit breakers concerned and to stop supplying the lines as soon as possible.

The passive and active methods are of an affordable cost for islanding detection of the new PV installation compared to communication based method. Furthermore, the passive methods have a large non detection zone for larger values of $Q_{f}$. Thus, islanding situation for our new installation should be detected by one of the active methods.

In order to provide a comparing analysis for the main simulated active methods (AFD, SFS and SMS), the NDZ in $Q_{f}$ (RLC load quality factor) and $f_{0}$ (resonant frequency) space for each one was plotted with a simulated evaluation of the duration of the islanding detection and the current THD. Simulations were carried out under Matlab/Simulink environment in order to study the effectiveness of the different active methods to detect islanding situation in the new PV system, provoked by one of the causes mentioned in Section 5.1.

The basic data of the studied PV installation are given in Table 2.
Table 2. Basic data of the studied system

\begin{tabular}{|c|c|}
\hline Parameters & Value \\
\hline Grid Voltage & $220 \mathrm{~V}$ \\
\hline Grid Frequency & $50 \mathrm{~Hz}$ \\
\hline $\begin{array}{c}\text { Inverter input DC voltage from } \\
\text { the PV }\end{array}$ & $200 \mathrm{~V}$ \\
\hline Load resistance & $6 \Omega$ \\
\hline Load reactance & $7 \mathrm{mH}$ \\
\hline Load capacitor & $1.3 \mu \mathrm{F}$ \\
\hline Load quality factor $Q_{f}$ & 2.58 \\
\hline Filter inductance & $60 \mathrm{mH}$ \\
\hline
\end{tabular}

\section{Simulation results and discussion}

As laid out in Fig. 10, the islanding detection duration when AFD method is used is $0.15 \mathrm{~s}$, which remains lower than the maximum duration of $2 \mathrm{~s}$ required by IEEE1574 standard [3].

According to Fig. 11, the THD value of the inverter current with the AFD method is $5.22 \%$ little more than $5 \%$, the threshold limit authorized by the same standard. Fig. 12 and Fig. 13 show that both of DDT and THD inverter's current improved with the SFS method used to detect the islanding. ${ }_{\text {H }}$ The THD of the SFS inverter's current value is $3.26 \%$ and the time detection is 0.1s. As one can see also, from Fig. 14 and Fig. 15, SMS islanding detection method has the best THD of about $1.3 \%$ and DDT is of about $0.28 \mathrm{~s}$. The performances of each method in comparison with the IEEE1574 standard are given in Table 3. The evaluation results of the main active methods for islanding detection in the grid connected photovoltaic system according to the criterion of their zone of nondetection are summarized in Fig. 16.

According to Fig. 16, the NDZ of the SMS islanding detection method is the narrowest than that of AFD and SFS IDMs. Furthermore, SMS Method does not degrade the power quality compared to the other active methods. Thus, the SMS method has been selected to detect any islanding situation for the new PV installation connected to OCP Group grid.

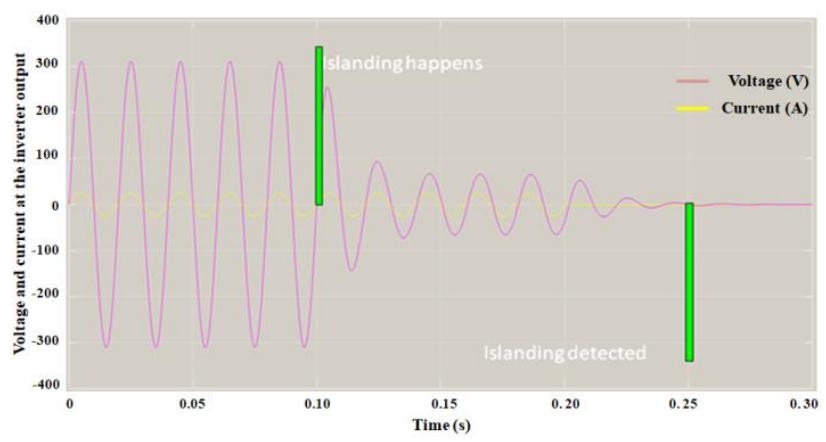

Figure. 10 Duration of detecting islanding with the AFD method 


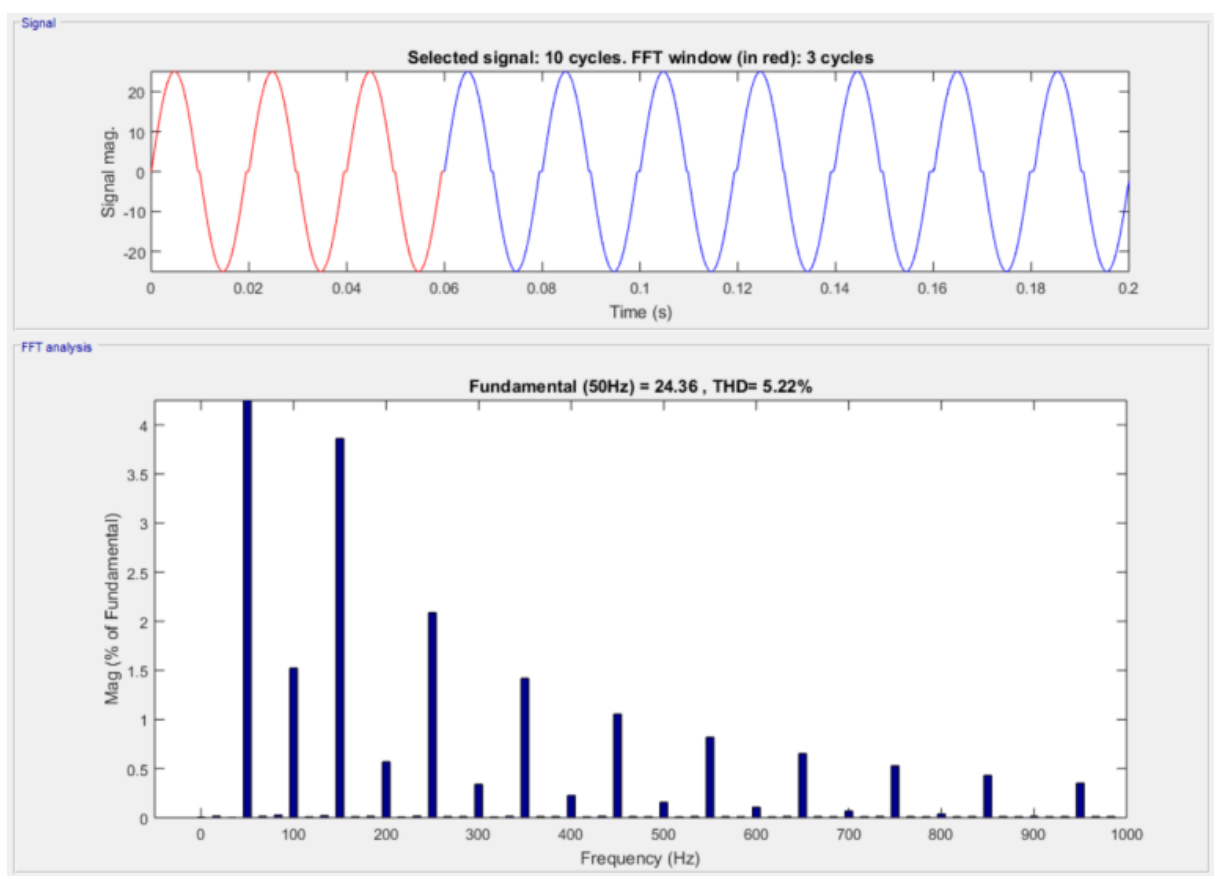

Figure. 11 THD of the inverter current with the AFD method

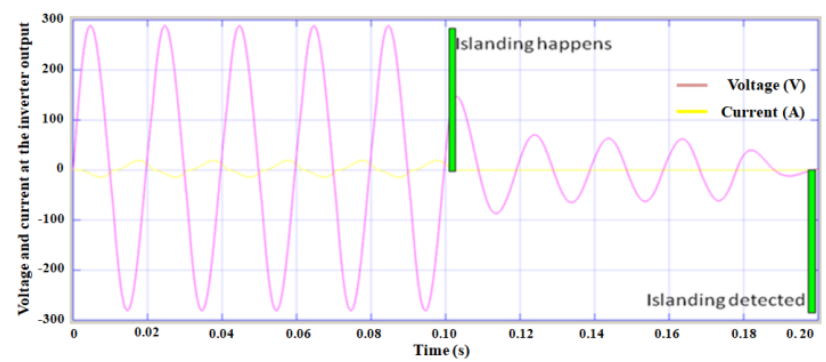

Figure. 12 Duration of detecting islanding with the SFS method

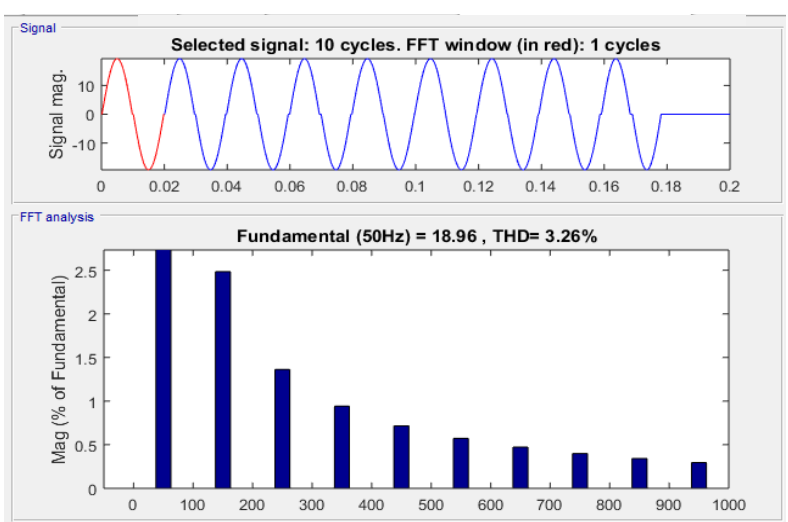

Figure. 13 THD of the inverter current with the SFS method

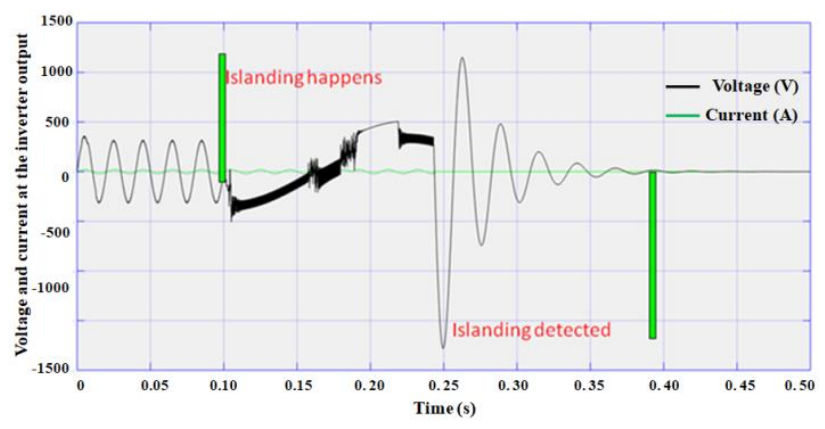

Figure. 14 Duration of detecting islanding with the SMS method

Table 3: Summary of simulated methods performances

\begin{tabular}{|c|c|c|c|c|}
\hline $\begin{array}{c}\text { Performance } \\
\text { criteria }\end{array}$ & $\begin{array}{c}\text { IEEE1574 } \\
\text { standard } \\
{[\mathbf{3}]}\end{array}$ & $\begin{array}{c}\text { AFD } \\
\text { method } \\
{[\mathbf{2 5}]}\end{array}$ & $\begin{array}{c}\text { SFS } \\
\text { method } \\
{[\mathbf{2 6}]}\end{array}$ & $\begin{array}{c}\text { SMS } \\
\text { method } \\
{[\mathbf{2 7}]}\end{array}$ \\
\hline $\begin{array}{c}\text { Duration of } \\
\text { the } \\
\text { detection }\end{array}$ & $2 \mathrm{~s}$ & $0.15 \mathrm{~s}$ & $0.1 \mathrm{~s}$ & $\mathbf{0 . 2 8 s}$ \\
\hline $\begin{array}{c}\text { Total } \\
\text { Harmonic } \\
\text { distortion }\end{array}$ & $5 \%$ & $5.22 \%$ & $3.26 \%$ & $\mathbf{1 . 3 \%}$ \\
\hline $\begin{array}{c}\text { Non } \\
\text { Detection } \\
\text { Zone }\end{array}$ & Noecification & Acceptable & Good & Best \\
\hline
\end{tabular}




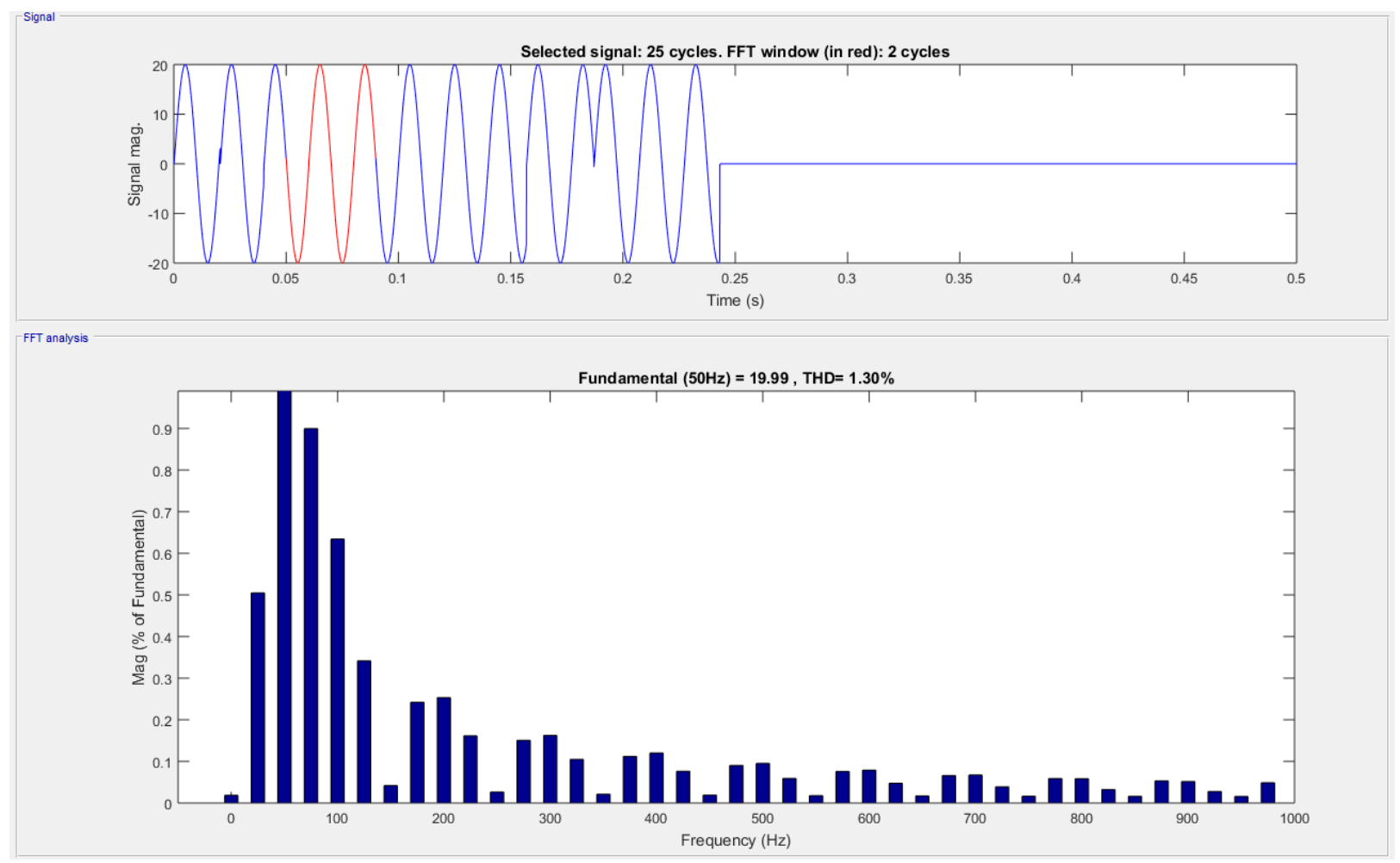

Figure. 15 THD of the inverter current with the SMS method

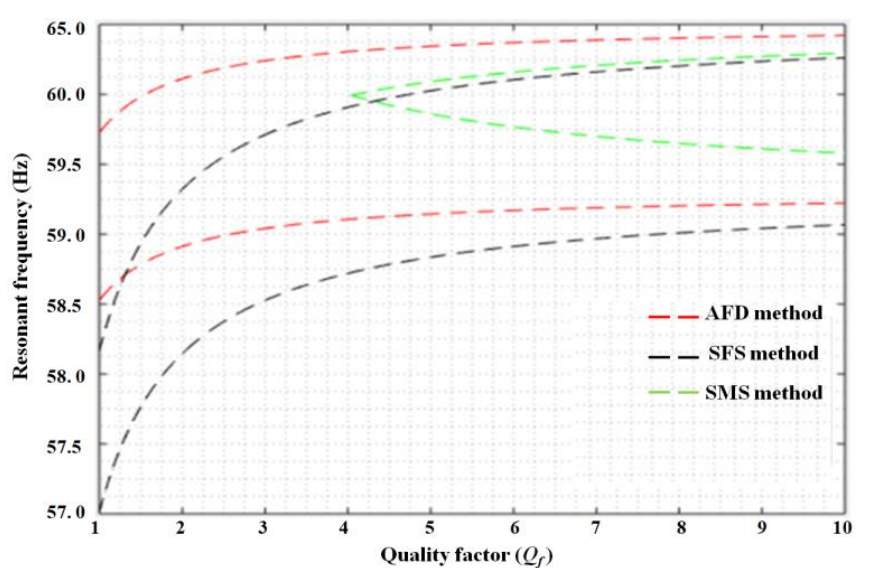

Figure. 16 NDZ area of AFD, SFS and SMS IDMs

\section{Conclusion}

This paper is a contribution to comprehensive study of the islanding situation of the new photovoltaic generators to be connected to LVs grid of OCP Group and presents the solution adopted among the main unintentional islanding detection methods that can be classified into passive, active and communication based methods. The definition of the way in which the PV generators will beintegrated to the network of OCP group allows establishing the cases in which the new PV installation is unintentionally isolated from the electrical network, which are: load shedding of the switchboard MV23EM15 (Mode 3), blackout (Mode 4) and Disturbances in the internal network of the thermal power plant. The study concludes that the passive methods have no effect on the power quality but they have a large non detection zone for larger values of Load quality factor. The communication based methods do not have a non detection zone; however, they are quite costly. The active techniques offer a compromise between the two; they have a relatively low non-detection zone and acceptable energy quality with an affordable cost.

The comparison on the main active methods (AFD, SFS and SMS) for islanding detection in the grid connected photovoltaic system (PV) is based on three parameters: the Non-Detection Zone (NDZ), the Detection Duration Time (DDT) and Total Harmonic Distortion (THD) of each method. These performance criteria are compared with the limit thresholds authorized by the IEEE 1574 standard, which are 5\% for THD and 2 seconds for DDT. The simulation results show that the Slip Mode Frequency Shift (SMS) method appears to have a small NonDetection Zone with a better current THD and DDT of $1.3 \%$ and $0.28 \mathrm{~s}$, respectively. Thus, it is considered as a better implementation option for our application (small PV installation connected to OCP Group grid).

The results of this study are part of a continuing thesis work. Further research with the aim of developing new islanding detection structures is underway. These new structures will also be an asset for university research programs and industrial utilizations. 


\section{Conflicts of Interest}

The authors declare no conflict of interest.

\section{Author Contributions}

Each author's contribution is as follows: Conceptualization, Fatima Chanaa and Radouane N'ait Zarri; methodology, Fatima Chanaa, Radouane N'ait Zarri, Elhadi Baghaz and Mohammadi Benhmida; software, Fatima Chanaa and Radouane N'ait Zarri; validation, Fatima Chanaa, Radouane N'ait Zarri, Elhadi Baghaz and Said Bounouar; formal analysis, Fatima Chanaa, Radouane N'ait Zarri, Elhadi Baghaz and Charaf Hajjaj; investigation, Fatima Chanaa, Houssam Amiry, Bouchaib Zohal, Mohammadi Benhmida, and Said Yadir; resources, Mohammadi Benhmida; data curation, Fatima Chanaa and Radouane N'ait Zarri; writing - original draft preparation, Fatima Chanaa, Rachid Bendaoud, Elhadi Baghaz, Charaf Hajjaj and Said Bounouar; writing - review and editing, Fatima Chanaa, Elhadi Baghaz, Rachid Bendaoud, Charaf Hajjaj and Mohammadi Benhmida; visualization, Fatima Chanaa, Mohammadi Benhmida, Houssam Amiry, Bouchaib Zohal and Said Yadir; supervision, Mohammadi Benhmida and Fatima Chanaa; project administration, Fatima Chanaa and Mohammadi Benhmida.

\section{References}

[1] International Energy Agency, Technology Roadmap: Solar Photovoltaic Energy, France, 2014.

[2] K. Naraghipour, K. Ahmed, and C. Booth, "A Comprehensive Review of Islanding Detection Methods for Distribution Systems", In: Proc. of 2020 9th International Conference on Renewable Energy Research and Application (ICRERA), Glasgow, UK, pp. 428-43, 2020.

[3] Inverters, Converters, Controllers and Interconnection System Equipment for Use With Distributed Energy Resources, UL1741 Standard, 2010.

[4] Interconnecting Distributed Resources with Electric Power Systems, IEEE 1547 Standard, 2003.

[5] IEEE Recommended Practice for Utility Interface of Photovoltaic (PV) Systems, IEEE 929-2000 Standard, 2000.

[6] Ch. R. Reddy and K. H. Reddy, "Islanding Detection Techniques for Grid Integrated Distributed Generation -A Review", International Journal of Renewable Energy Research, Vol. 9, No. 2, pp. 960-977, 2019.
[7] J. Huang, C. Jiang, and R. Xu, "A review on distributed energy resources and MicroGrid", Renewable and Sustainable Energy Reviews, Vol. 12, pp. 2472-2483, 2008.

[8] S. B. A. Bukhari, M. Saeed Uz Zaman, R. Haider, Y. S. Oh, and C.H. Kim, "A protection scheme for microgrid with multiple distributed generations using superimposed reactive energy", International Journal of Electrical Power \& Energy Systems, Vol. 92, pp. 156-166, 2017.

[9] M. R. Islam, Advances in solar photovoltaic power plants, green energy and technology, Springer-Verlag Berlin Heidelberg, 2016.

[10] Q. Sun, J. M. Guerrero, T. Jing, J. C. V. Quintero, and R. Yang, "An islanding detection method by using frequency positive feedback based on FLL for single-phase microgrid", IEEE Transactions on Smart Grid, Vol. 8, No. 4, pp. 1821-1830, 2016.

[11] W. Bower and M. Ropp, "Evaluation of islanding detection methods for photovoltaic utility interactive power systems", Report IEAPVPS T5-09, 2002.

[12] W. Bower and M. Ropp, "Evaluation of islanding detection methods for utility interactive inverters in photovoltaic systems", Sandia National Laboratories Report, 2002.

[13] W. Xu, G. Zhang, C. Li, W. Wang, G. Wang, and J. Kliber, "A Power line signaling based technique for anti-islanding protection of distributed generators-part I: scheme and analysis", IEEE Transactions on Power Delivery, Vol. 22, No. 3, pp. 1758-1766, 2007.

[14] W. Wang, J. Kliber, G. Zhang, W. Xu, B. Howell, and T. Palladino, "A Power Line Signaling Based Scheme for Anti-Islanding Protection of Distributed Generators-Part II: Field Test Results", IEEE Transactions on Power Delivery, Vol. 22, No. 3, pp. 1767-1772, 2007.

[15] J. H. Kim, J. G. Kim, Y. H. Ji, Y. C. Jung, and C. Y. Won, "An Islanding Detection Method for a Grid-Connected System Based on the Goertzel Algorithm", IEEE Transactions on Power Electronics, Vol. 26, No. 4, pp. 1049-1055, 2011.

[16] B. Anudeep, R. Nale, and M. Biswal, "Comparative assessment of passive islanding detection techniques for microgrid", In: Proc. of 2017 International Conference on Innovations in Information, Embedded and Communication Systems (ICIIECS), pp. 1-5, 2017.

[17] R. Haider, C. H. Kim, T. Ghanbari, S. B. A. Bukhari, M. Zaman, S. Baloch, and Y. S. Oh, "Passive islanding detection scheme based on 
autocorrelation function of modal current envelope for photovoltaic units", IET Generation, Transmission \& Distribution, Vol. 12, No. 3, pp. 726-736, 2018.

[18] C. Li, C. Cao, Y. Cao, Y. Kuang, L. Zeng, and B. Fang, "A review of islanding detection methods for microgrid", Renewable and Sustainable Energy Reviews, Vol. 35, pp. 211220, 2014.

[19] F. D. Mango, M. Liserre, A. Dell'Aquila, and A. Pigazo, "Overview of anti-islanding algorithms for PV systems. part I: passive methods", In Proceedings of the 2006 12th International Power Electronics and Motion Control Conference, pp. 1878-1883, 2006.

[20] M. A. Redfern, O. Usta, and G. Fielding, "Protection against loss of utility grid supply for a dispersed storage and generation unit", IEEE Trans Power Delivery, Vol. 8, No. 3, pp. 948954, 1993.

[21] W. Xu, G. Zhang, C. Li, W. Wang, G. Wang, and J. Kliber, "A power line signaling based technique for anti-islanding protection of distributed generators-part I: scheme and analysis", IEEE Trans Power Delivery, Vol. 22, No. 3, pp.1758-1766, 2007.

[22] M. S. Kim, R. Haider, G. J. Cho, C. H. Kim, C. Y. Won, and J. S. Chai, "Comprehensive review of islanding detection methods for distributed generation systems", Energies, Vol. 12, pp. 837, 2019.

[23] T. Z. Bei, “Accurate active islanding detection method for grid-tied inverters in distributed generation", IET Renew. Power Gener, Vol. 11, pp. 1633-1639, 2017.

[24] Z. Ye, A. Kolwalkar, Y. Zhang, P. Du, and R. Walling, "Evaluation of anti-islanding schemes based on nondetection zone concept", In: Proc. of Power Electronics Specialist Conference, Vol. 4, pp. 1735-1741, 2003.

[25] Z. Li, X. Liu, X. Liu, X. Wang, and H. Wang, "Active Frequency Drift Islanding Detection Method with the Positive Feedback by Absolute Value of Voltage Frequency", In: Proc. of 2018 Chinese Automation Congress (CAC), pp. 578582, 2018.

[26] A. Y. Hatata, El-H. Abd-Raboh, and B. E. Sedhom, "Proposed Sandia Frequency Shift for Anti-Islanding Detection Method Based on Artificial Immune System", Alexandria Engineering Journal, Vol. 57, No. 1, pp. 235245, 2018.

[27] J. Kan, H. Jiang, Y. Tang, D. Wu, Y. Wu, and J. $\mathrm{Wu}$, "Comparison of Three Active-FrequencyDrift Islanding Detection Methods for Single-
Phase Grid-Connected Inverters", Journal of Power Electronics, Vol. 19, No. 2, pp. 509-518, 2019. 